\title{
Screening University Students for Rheumatic Heart Disease
}

\author{
Azza Mam Abul Fadl and Ahmed Ata Sobeih* \\ Pediatric Department, Faculty of Medicine, Benha University, Benha, Egypt
}

*Corresponding author: Ahmed Ata Sobeih, Department of Pediatric, Faculty of Medicine, Benha University, Egypt, Tel: +20223494183, E-mail: azza_abulfadl@yahoo.com

Received date: March 28, 2018; Accepted date: April 22, 2018; Publication date: April 29, 2018

Citation: Abul Fadl AM, Sobeih AA (2018) Screening University Students for Rheumatic Heart Disease. J Prev Med Vol.3 No.2: 13.

Copyright: (c) 2018 Sobeih AA, et al. This is an open-access article distributed under the terms of the Creative Commons Attribution License, which permits unrestricted use, distribution and reproduction in any medium, provided the original author and source are credited.

\section{Abstract}

Introduction: Screening using echocardiography is currently recognized as the state of art tool for early detection of Rheumatic heart disease (RHD). Unfortunately, primary and periodic examination freshman university students, does not include examination of the heart via echocardiography.

Aim: To screen freshman medical students for RHD and other risk factors that can aggravate the progression of the heart disease.

Methods: Freshman (first year) medical students were exposed to full cardiovascular examination. Four hundred students were targeted only 150 completed the exam. All students underwent a full anthropometric assessment for weight, height and Body mass index and screening for high blood pressure. A full cardiac exam was done for 100 students using a portable echocardiography machine.

Results: Overall prevalence of obesity and overweight was $6.7 \%$ and $11.3 \%$ respectively. Pre-hypertension and hypertension were detected in $10.7 \%$ and $8 \%$ respectively. By echocardiography exam, mitral valve prolapse was detected in $4(4 \%)$ and RHD in 3 students (3\%) which was mostly mitral regurgitation was the main lesion in $100 \%$ of the cases. There was a direct positive significant correlation between overweight, obesity and hypertension at $\mathrm{P}<0.001$.

Conclusion: Screening for cardiovascular disease for freshman student is important to reveal hidden cardiovascular disease. Echocardiography is helpful tool in early identification of silent disease.

Keywords: Echocardiography; Screening; Congenital heart disease; Rheumatic heart disease; Hypertension; Prehypertension; Freshman medical students

\section{Introduction}

Cardiovascular disease in children and adolescents encompasses hypertensive disease, adult congenital and acquired heart disease including rheumatic heart disease (RHD). Unsuspected heart problems are a major cause of sudden death in the pediatric age group. In developing countries such as Taiwan an annual incidence of sudden death in the pediatric age group was reported to be 6.4 per 1000000 . Acute heart failure of unknown etiology was found in $62 \%$ of these cases and only $19 \%$ had known cardiovascular disease. Of those in whom sudden death was attributed to a cardiac cause, $79 \%$ died during sporting activities [1]

Early detection of cardiovascular disease (CVD) among adolescents is important as the peak age of occurrence of diseases as RHD and hypertension occurs in late childhood and early adolescence and is a major public health problem in many low and middle income countries [2-4]. The emergence of echocardiographic screening provides the opportunity for early disease detection and intervention [5]. Prevalence studies using echocardiography as a screening tool is reporting the detection of RHD at 12.5 years was 23.5/1000. The incidence of RHD is coming close to incidence of rheumatic fever (RF), with 27.6 new cases per year in indigenous areas in Australia $[6,7]$.

However there is still much debate around the use of echocardiography as a tool for screening for early detection of RHD [7]. Hence, this study was conducted to assess the role of echocardiography as a tool for screening freshman university students for cardiovascular disease for early referral and treatment of in order to reduce the complications of CVD.

\section{Methods}

This is an observational nonrandomized cross- sectional study that targeted initially the 400 enrolled students. Out of the 400 , only 150 freshman university students attending the first year at Benha Faculty of Medicine agreed to participate. Ethical clearance was obtained from University and consent was obtained from the subjects. Inclusion criteria included healthy first year medical students, aged between 17-18 years. The exclusion criteria included subjects with any known acute or chronic disease and those who were taking any medication. All students underwent complete history taking through a previously designed questionnaire. Anthropometric assessment for weight to the nearest gram, height to the nearest $\mathrm{cm}$ was done using standardized weight and standing height scales. They were interpreted by z-scores using the weight-for-age and height-for-age Egyptian growth charts and used to estimate the body mass index. Examination of the blood pressure 
measurement was done by a mercury sphygmomanometer using standard methods. Local cardiac examination was done by careful auscultation. Systematic echocardiography (echo) to assess cardiac chambers and valves was done for all the students using a GE vivid e portable ultrasound machine, with a $3 \mathrm{MHz}$ probe, at the university. Echo was combined with 2D ultrasound to assess heart chambers dimesnsions and condition of the valves and septum.

Left ventricular function was assessed using M-mode. Color Doppler was used to evaluate blood flow across the valves of the heart to detect valvular disease or congenital defect in the heart. All suspected cases detected at university had a second evaluation by an adult cardiologist to determine whether they had or did not have left sided valve lesion by detailed echocardiographic examination.

\section{Statistical Analysis}

The collected data were organized, tabulated and statistically analyzed using SPSS version 20 (SPSS Inc; Chicago, Illinois), running on IBM compatible computer with Microsoft Windows 7 Operating System. The qualitative data for the rates of breastfeeding, literacy, mortality rates and nutritional indices were presented as discrete data per country and also presented in mean and standard deviation for the region.

Spearman rank correlation coefficient was used to measure the strength and direction of the linear relationship between two variables. The level of significance cut off used was $P<0.05$.

\section{Ethical considerations}

The work of the paper was in compliance with the ethical principles of Helsinki Declaration (1964).

\section{Results}

The study was conducted for 150 students but only 100 cases agreed to an echo exam. Findings are [presented in tables 1 to 4 as follows:

Table (1) presents the frequency distribution of overweight and obesity using the Body mass index. The prevalence of obesity and overweight were $6.7 \%$ and $11.3 \%$ respectively in the population under study.

Table (2) presents the frequency distribution of the hypertension and pre-hypertension. Pre-hypertension and hypertension were detected in among $10.7 \%$ and $8 \%$ respectively in the population under study.

Table (3) presents the relationship between the overweight and obesity with the presence of hypertension or prehypertension in the studied sample. There was a statistically positive correlation between overweight and obesity with prehypertension and hypertension at $\mathrm{P}<0.001$.

Table (4) presents the prevalence of findings by echocardiography examination of 100 students (50 cases with normal clinical examination refused an echo exam). The table shows that $93 \%$ of students had a normal study and $3(3 \%)$ students had rheumatic mitral regurge (MR) and $4(4 \%)$ of the students had mitral valve prolapse of these $2(2 \%)$ had mitral valve prolapse alone and $2(2 \%)$ students have mitral valve prolapse combined with MR.

Table 1: Frequency distribution of the studied sample according to the (ref) classification of overweight and obesity using the Body mass index (BMI).

\begin{tabular}{|l|l|l|l|}
\hline \multirow{2}{*}{ Variable } & & No (N=150) & \% (100\%) \\
\cline { 2 - 5 } BMI (kg/m2) & Normal weight & 123 & 82 \\
\hline & Overweight & 17 & 11.3 \\
\hline
\end{tabular}

Table 2: Frequency distribution of the studied sample according to (ref) classification blood pressure.

\begin{tabular}{|c|c|c|c|}
\hline \multicolumn{2}{|l|}{ Variable } & \multirow{2}{*}{$\begin{array}{l}\text { No. }(\mathbf{N}=\mathbf{1 5 0}) \\
122\end{array}$} & \multirow{2}{*}{$\begin{array}{l}\%(100 \%) \\
81.3\end{array}$} \\
\hline & Normal & & \\
\hline & Pre hypertension* & 16 & 10.7 \\
\hline Blood pressure & Hypertension $^{*}$ & 12 & 8 \\
\hline
\end{tabular}


Table 3: Relationship between the overweight and obesity with the presence of hypertension or pre-hypertension among the studied sample.

\begin{tabular}{|c|c|c|c|c|c|c|}
\hline & & & \multicolumn{3}{|c|}{ Blood pressure } & \multirow[t]{2}{*}{ Total } \\
\hline & & & Normal & Pre hypertension & Hypertension & \\
\hline \multirow{6}{*}{ BMls } & \multirow{2}{*}{ Normal weight } & \multirow{2}{*}{ Count $\%$ Blood pressure } & 113 & 6 & 4 & 123 \\
\hline & & & $92.60 \%$ & $37.50 \%$ & $33.30 \%$ & $82.00 \%$ \\
\hline & \multirow{2}{*}{ Overweight } & \multirow{2}{*}{ Count \% Blood pressure } & 6 & 10 & 1 & 17 \\
\hline & & & $4.90 \%$ & $62.50 \%$ & $8.30 \%$ & $11.30 \%$ \\
\hline & \multirow{2}{*}{ Obesity } & \multirow{2}{*}{ Count $\%$ Blood pressure } & 3 & 0 & 7 & 10 \\
\hline & & & $2.50 \%$ & $0.00 \%$ & $58.30 \%$ & $6.70 \%$ \\
\hline \multirow{2}{*}{ Total } & & \multirow{2}{*}{ Count \% Blood pressure } & 122 & 16 & 12 & 150 \\
\hline & & & $100.00 \%$ & $100.00 \%$ & $100.00 \%$ & $100.00 \%$ \\
\hline
\end{tabular}

Table 4: Frequency distribution of echocardiography findings among the population under study after referral and confirmation of final diagnosis.

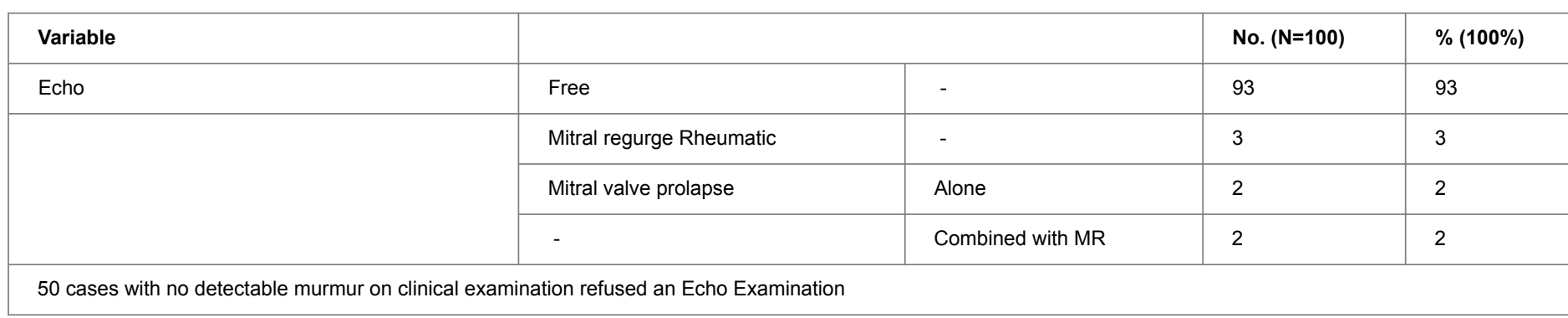

\section{Discussion}

The screening of freshman students detected overweight in $11.3 \%$, and obesity in $6.7 \%$ of students. Our findings are similar to those reported by a study done in Puducherry in 2016, for 1005 students, in which prevalence of obesity was 6.6\% [8]. Our results are much higher than prevalence rates of obesity in Nigeria (1.9\%) [9], and also another study for 320 students of 3 rd year at Institute of Medical Technology in Iran, conducted between December 2011 and May 2012, who reported a prevalence of obesity of $2.2 \%$ [10]. Our results are lower than study done in first-year students at Trnava University in Slovakia the study population consisted of 122 first-year students with obesity prevalence of $10.7 \%$ [11] also another study done on Brazil that reported an obesity prevalence of $8.4 \%$ [12]. The differences in the obesity prevalence may be attributed to sociocultural factors in which poor life styles as sedentary lives and lack of exercise augmented by poor dietary habits such as junk foods, sugary beverages and high carb foods intake, play a major role. Recently the issue of obesity has been implicated to be due to genomic variations particularly related to Leptin $[13,14]$.

The screening also detected hypertension in $8 \%$ and prehypertension in $10.7 \%$ of the freshman students. These findings are similar to those reported by a study from Jaipur, where prevalence of definite hypertension was $7.2 \%$ for adolescents aged 13-17 [15]. Our findings are also similar to those reported by a study in Delhi University, in India, for 335 first year medical students, whereby prevalence of hypertension was $7.16 \%$ [16] and in South India among young adults (7.1\%) [17]. Similar prevalence rates were shown by a survey of 610 college students who were screened for hypertension where prevalence rates of hypertension were $7.7 \%$. Higher rates of hypertension were observed among males who were overweight and students who reported that they sleep for less than 5 hours [18].

Ambient air pollution is linked to CVD and especially related to exposure to PM 2.5 [19] which explain the high prevalence in freshman students living in areas with high pollution. Modifiable lifestyle factors such as the increased consumption of unhealthy foods, physical inactivity exposure to pollution are important independent contributors to the increasing burden of hypertension and CVD [20].

These findings were lower than those reported in Sudan among rural population where prevalence of hypertension among their young adults was $15.8 \%$ [21]. Our findings were higher than those reported in Turkey among high school students $4.4 \%$ [22]. While even lower rates were reported for youth in Southwest of Nigeria where prevalence rates of hypertension were $3.3 \%$ [23]. The likely reasons for the difference between the prevalence of hypertension in this study 
and other studies might be the use of different age groups, differing research methods and definitions of blood pressure (BP), as well as differences in reported prevalence and risk estimates. It is possible too, that the geographical location may account for the difference in distribution of BP. It has been reported that regional difference exists in the $\mathrm{BP}$ among pediatrics and adult populations from various geographic areas of the world.

Our study shows that there is a significant and direct relationship between obesity and overweight with hypertension. Many similar studies, are in line with our findings, and have confirmed a direct relationship between BMI and BP. Studies conducted in Portugal [24] and in China [25] and in Iran [26] indicated that average of blood pressure significantly increased along with the BMI. It could be noted that dietary habits and pattern of physical activity among the obese and overweight people are important factors associated with hypertension.

However, another study conducted among 983 school children in Ahmedabad Municipal Corporation schools revealed that there was no positive correlation between high BP and overweight and obesity [27]. The differences may be related to age groups and methodologies used to correlate these findings.

The prevalence of RHD by clinical examination was $1.3 \%$. While prevalence by echo screening was 3\%. Other workers [28] have shown that screening by echo as compared to auscultatory methods of screening revealed a much higher prevalence of acquired and congenital heart diseases and indicate the value and importance of echo screening for detection of heart diseases. They compared the classical approach of auscultation screening with stethoscopes to screening with portable echocardiography. Case detection of asymptomatic RHD was up to ten fold higher with echocardiography than auscultation. Rapid diffusion of portable echocardiography technology was associated with a large number of research activities to quantify the prevalence of RHD [28].

The results for echocardiography (echo) screening revealed a higher prevalence of RHD than those reported at national level by previous workers, which ranged from 3 to 9 per a thousand [29]. All the cases presented with mitral regurge (MR). Other workers who used echo as the primary screening method [30] have also reported a higher prevalence rates than auscultation methods and concluded that echo is a more sensitive tool for early detection of cases, probably reflecting a higher prevalence of carditis that is building up into chronic established RHD. Hence, early detection and treatment can prevent progression [31,32].

Disease severity varies over time, when workers [33] used a multistage model in which surgeries and deaths were evaluated in 591 patients with RHD, one half of cases with severe disease proceeded to valve surgery by 2 years, and $10 \%$ were dead within 6 years. Those diagnosed with moderate RHD, had a similar chance of disease regression or progression over time. Hence, early detection, by screening using echo, can prevent disability and death.

In our study the prevalence of mitral valve prolapse (MVP) was commonest congenital valvular anomaly and was detected by echocardiography in $4 \%$ of the students. Although other workers have reported similar prevalence rates of about 3\% [34] these estimates are still high. It is important to distinguish between mitral proplapse and rheumatic mitral valve affection. The echocardiographic features of rheumatic MR are generally easy to recognize. Commissural fusion, involvement of other valves, most commonly the aortic, are clues to distinguish MVP from RHD [34]. Classic prolapse is defined as a maximum superior displacement of one or both mitral leaflets of $>2 \mathrm{~mm}$ relative to the line connecting the annular hinge points during systole, and a maximum leaflet thickness of $>5 \mathrm{~mm}$. In addition, "non-classic" prolapse is also described, with maximum displacement of $>2 \mathrm{~mm}$ but a leaflet thickness $<5 \mathrm{~mm}$. Subjects with classic prolapse are at higher risk of complications than those with the non-classic form $[35,36]$.

Previous screening studies relied on clinical examination only for detection of cases of RHD and rheumatic prolapse, while echocardiography was used for confirmation. Many of these past population-based epidemiologic surveys have thereby underestimated the prevalence of RHD. Echocardiography is known to be more sensitive than auscultation for the detection of pathologic valve disease. Meira et al., [37] reported that in $34 \%$ of their patients with carditis, clinical examination after the acute phase showed normal findings, although progression to chronic sub clinical valvular disease was confirmed by echocardiography in $82 \%$ of such cases. According to Marijon et al., [29] systematic screening with echocardiography, as compared with clinical screening, reveals a much higher prevalence of RHD. In Egypt a population of 3062 school children surveyed by echo in Aswan by [38] revelaed a prevalence rate of definite RHD in 23 per thousand Mitral valve affection (mainly regurgitation )was present in $96 \%$, aortic regurgitation in $2.9 \%$ and combination of both in $1.4 \%$. Left ventricular function was normal in all patients. Auscultation revealed a murmur in $7.1 \%$ of children with echocardiographic evidence of rheumatic heart disease showing a 14 fold increased detection rate by echocardiography [38]

The World Health Organization (WHO) states that, echocardiographically diagnosed, clinically silent rheumatic valve involvement should be managed as RHD until proved otherwise. WHO also states that, it is important to recognize that technical expertise with color flow Doppler echocardiography is necessary to make an accurate diagnosis of sub clinical carditis and to avoid over diagnosis. In developing countries, where the majority of rheumatic fever (RF) cases occur, such expertise and facilities are available in only a limited number of centres. As a result, the impact of erroneous diagnoses of rheumatic carditis based on sub-clinical echocardiographic findings should not be underestimated. Still, the high sensitivity of Doppler echocardiography, which is debated to be questionable, when used as screening test that can detect and reverse a disabling condition is a cost effective and life-saving tool. The prevalence of RF carditis is significantly higher than RHD by echocardiography than those reported by clinical examination and auscultation alone, hence, the interpretation of findings by echo exam should undergo careful assessment [39-41]. 
It is concluded that freshman students on Benha faculty of medicine suffer from a variety of morbidities from CVD including prehypertension, hypertension, and RHD. These diseases are linked with underlying risk factors of which overweight, obesity and poor living conditions are the common underlying causes. Recently suggestions have been made that susceptibility to RHD may begin early infancy [42] by exposure to ambient air pollution [43] and infection and possible by mode of early infant feeding practices [44].

RHD is a preventable disease, screening programs for freshman students for CVDs primarily hypertension and heart disease using echocardiograms is important for prevention of moribund and potentially fatal diseases as RHD and Hypertrophic obstructive cardiomyopathy (HOCM) and aortic valve anomalies. Policies and programs should be adopted by governments in this regards.

\section{Disclosures}

None

\section{Acknowledgements}

We acknowledge the support provided by Nasser Abdou Kolkailah, late professor of pediatrics who passed away during the conduction of this work.

\section{References}

1. Yu CH, Lue HC, Wu SJ, Chen MR (2009) Heart disease screening of schoolchildren in Taiwan. Arch Paediatr Adolesc Med 163: 233-237.

2. Carapetis JR, Steer AC, Mulholland EK, Weber M (2005) The global burden of group a streptococcal diseases. Lancet Infect Dis 5 : 685-694.

3. Zühlke LJ, Steer AC (2013) Estimates of the global burden of rheumatic heart disease. Glob Heart 8: 189-195.

4. Seckeler MD, Hoke TR (2011) The worldwide epidemiology of acute rheumatic fever and rheumatic heart disease. Clin Epidemiol 3: 67.

5. Roberts K, Cannon J, Atkinson D, Brown A, Maguire G, et al. (2017) Echocardiographic screening for rheumatic heart disease in indigenous Australian children: A cost-utility analysis. J Am Heart Assoc 6: e004515.

6. Lawrence JG, Carapetis JR, Griffiths K, Edwards K, Condon JR, et al. (2013) Acute rheumatic fever and rheumatic heart disease: Incidence and progression in the northern territory of Australia 1997-2010. Circ 113.

7. Zühlke L, Mayosi BM (2013) Echocardiographic screening for subclinical rheumatic heart disease remains a research tool pending studies of impact on prognosis. Curr Cardiol Rep 15: 343.

8. Kavitha B, Bhuvaneswari k (2016) Prevalence of sustained hypertension among adolescent school children in Puducherry. $J$ Basic Appl Med Res 5: 649-655.

9. Ujunwa FA, Ikefuna AN, Nwokocha AR, Chinawa JM (2013) Hypertension and prehypertension among adolescents in secondary schools in Enugu, South East Nigeria. Ital J Pediatr 39: 70.
10. Saeed S, Ali A, Khawaja R, Shaikh IA, Shah I, et al. (2013) Relationship between $\mathrm{BMI}$ and blood pressure among students of 3rd year at institute of medical technology (DUHS). medical channel. MC 19: 5-8.

11. Hujova $Z$ (2013) The prevalence of obesity and hypertension among first-year students at trnava university in Slovakia. Int J Med 5: 361-367.

12. Bloch KV, Klein CH, Szklo M, Kuschnir MC, Abreu GD, et al. (2016) ERICA: Prevalences of hypertension and obesity in brazilian adolescents. Rev Saude Publica 50: 9.

13. Paracchini V, Pedotti P, Taioli E (2005) Genetics of leptin and obesity: A huge review. Am J Epidemiol 162: 101-114.

14. Khader $\mathrm{Y}$, Abdelrahman $\mathrm{M}$, Abdo N, Awad S, Al-Sharif M, et al. (2016) Exposure to air pollution and pregnancy outcomes in the east mediterranean region: A systematic review. Int J Pediatr Endocrinol 4: 1255-1271.

15. Gupta R, Goyle A, Kashyap S, Agarwal M, Consul R, et al. (1998) Prevalence of atherosclerosis risk factors in adolescent school children. J Heart 50: 511-515.

16. Chhabra P, Grover VL, Aggarwal K, Kanan AT (2006) Nutritional status and blood pressure of medical students in Delhi. Indian J Community Med 31: 248-251.

17. Reddy VS, Jacob GP, Ballala K, Ravi C, Ravi B, et al. (2015) A study on the prevalence of hypertension among young adults in a coastal district of Karnataka, South India. Int J Biomed Res 3: 32-39.

18. Tadesse T, Alemu H (2014) Hypertension and associated factors among university students in Gondar, Ethiopia: A cross-sectional study. BMC Public Health 14: 937.

19. Yu H, Yu M, Gordon SP, Zhang R (2017) The association between ambient fine particulate air pollution and physical activity: A cohort study of university students living in Beijing. Int J Behav Nutr Phys Act 14: 136

20. Roberts JD, Voss JD, Knight B (2014) The association of ambient air pollution and physical inactivity in the United States. PLoS One 9: e90143.

21. Balla SA, Abdalla AA, Elmukashfi TA, Ahmed HA (2014) Hypertension among rural population in four states: Sudan 2012. Glob J Health Sci 6: 206.

22. Nur N, Çetinkaya S, Yilmaz A, Ayvaz A, Bulut MO, et al. (2008) Prevalence of hypertension among high school students in a middle Anatolian province of Turkey. J Health Popul Nutr 26: 88.

23. Akinkugbe FM, Akinwolere AO, Kayode CM (1999) Blood pressure patterns in Nigerian adolescents. West Afr J Med 18: 196-202.

24. Ribeiro J, Guerra S, Pinto A, Oliveira J, Duarte J, et al. (2003) Overweight and obesity in children and adolescents: Relationship with blood pressure, and physical activity. Ann Hum Biol 30: 203-213.

25. He Q, Ding ZY, Fong DY, Karlberg J (2000) Blood pressure is associated with body mass index in both normal and obese children. Hypertens 36: 165-170.

26. Soleymani GR, Nouri NM, Boriri T (2003) Normal range of blood pressure in 7-11 year old children in Zahedan. J Med Sci 5: 18-21.

27. Banker C, Jitesh C, Hyati KMK, Damor P (2013) A Study of prevalence of hypertension in school children . Gujarat Medical Journal. I.M.A.G.S.B. News Bulletin 8: 79-81. 
28. Marijon E, Ou P, Celermajer DS, Ferreira B, Mocumbi AO, Jet al. (2007) Prevalence of rheumatic heart disease detected by echocardiographic screening. N Engl J Med 357: 470-476.

29. Abul-Fadl A, Mourad MA (2014) systemic review of screening methods for rheumatic heart disease in Egypt: Potential role of echocardiography for community based surveys. Presented in the Euro Eco Imaging 2014 Conference held in Vienna, Austria from 3-6 December, 2014. (18th Annual Meeting of the European Association of Cardiovascular Imaging)

30. Carapetis JR, Hardy M, Fakakovikaetau T, Taib R, Wilkinson L, et al. (2008) Evaluation of a screening protocol using auscultation and portable echocardiography to detect asymptomatic rheumatic heart disease in Tongan schoolchildren. Nat Rev Cardiol 5: 411.

31. Kane A, Mirabel M, Touré K, Périer MC, Fazaa S, et al. (2013) Echocardiographic screening for rheumatic heart disease: Age matters. Int J Cardiol 168: 888-891.

32. Bhaya M, Panwar S, Beniwal R, Panwar RB (2010) High prevalence of rheumatic heart disease detected by echocardiography in school children. Echocardiogr 27: 448-453.

33. Cannon J, Roberts K, Milne C, Carapetis JR (2017) Rheumatic heart disease severity, progression and outcomes: A multi-state model. $J$ Am Heart Assoc 6: e003498.

34. Jones EC, Devereux RB, Roman MJ, Liu JE, Fishman D, et al. (2001) Prevalence and correlates of mitral regurgitation in a populationbased sample (the Strong Heart Study). Am J Cardiol 87: 298-304.

35. Iwanaga Y, Nishi I, Furuichi S, Noguchi T, Sase K, et al. (2006) Btype natriuretic peptide strongly reflects diastolic wall stress in patients with chronic heart failure: Comaparison between systolic and diastolic heart failure. J Am Coll Cardiol 47: 742-748.

36. Freed LA, Levy D, Levine RA, Larson MG, Evans JC, Fuller DL, Lehman B, Benjamin EJ. Prevalence and clinical outcome of mitralvalve prolapse. N Engl J Med 341: 1-7.

37. Narayanan K, Evanado AU, Teodorescu C, Reinier K, Nichols GA, et al. (2016) Mitral valve prolapse and sudden cardiac arrest in the community. Heart Rhythm 13: 498-503.

38. Meira ZM, Goulart EM, Colosimo EA, Mota CC (2005) Long term follow up of rheumatic fever and predictors of severe rheumatic valvar disease in Brazilian children and adolescents. Heart 91: 1019-1022.

39. Yacoub M, Kotit S (2012) An echocardiographic screening of school children for rheumatic heart disease in Aswan, Egypt. InQatar Foundation Annual Research Forum 2012. p. BMP120.

40. http://www.qscience.com/doi/abs/10.5339/qfarf.2012.BMP120

41. World health organization (2004) Rheumatic fever and rheumatic heart disease: Report of a who expert consultation, Geneva, 29 october-1 november, 2001. world health organization.

42. Marijon E, Celermajer DS, Tafflet M, El Haou S, Jani DN, et al. (2009) Rheumatic heart disease screening by echocardiography: the inadequacy of World Health Organization criteria for optimizing the diagnosis of subclinical disease. Circ 120: 663-668.

43. Phillips DI, Osmond C (2015) Is susceptibility to chronic rheumatic heart disease determined in early infancy? An analysis of mortality in Britain during the 20th century. Glob Cardiol Sci Pract 1: 59. 